\title{
Describing Connections between Science Content and Future Careers: Implementing Texas Curriculum for Rural At-Risk High School Students Using Purposefully-Designed Field Trips
}

\author{
Tommye Hutson \\ Baylor University \\ Susan Cooper \\ University of Wisconsin-Green Bay \\ Tony Talbert \\ Baylor University
}

The state of Texas has an 'essential knowledge' component in some high school science courses indicating that students be able to describe connections between academic science content and future jobs or training through effective exposure to course content. The participants in this study were from a small rural high school in central Texas. Each was labeled as 'at-risk' and self-identified an inability to describe those types of connections after earning credit in more than one science course with that 'essential knowledge' component. A career-focused field trip to a local vocational/technology training center was designed to address that particular deficit. This study followed a narrative multiple-case case study design. Data included school records, surveys, individual and focus group interviews, and field notes from observations during the field trip. The effectiveness of the field trip was evident as each participant was able to describe connections immediately following the excursion.

Keywords: Field trips; At-risk students; Narratives; Science pedagogy; Consequences of high-stakes testing.

Universally students often lament that academic content bears little meaning to their experience (Bialeschki, 2007; Hardre, Crowson, Debacker, \& White, 2007). Comments such as, Why do I have to learn that? or, When will I ever use this? resound in every classroom and in every discipline whether adolescents are engaged and participating or bored and frustrated. A good part of their vocalizing is likely peer-driven, normal and expected. However, some students actually realize very little connection between academic content and their lives or their futures (Hardre, 2007). For these students, school is simply a location and series of activities that consume seven or more hours of the day. In content areas where abstraction and analysis are necessary, such as higher mathematics and sciences, this disconnect can present particular frustrations for many adolescent students (Scarce, 1997; Kolb, 1984). The purpose of this study was to determine the efficacy of a purposefully designed field trip experienced by $12^{\text {th }}$ grade students from a small, rural central Texas high school. Because there is also a chronic lack of research dealing with issues predominant in rural schools and their students, this project offered an opportunity to increase the knowledge base on engagement of rural students with academic content (Hardre et al., 2007). Having taught in rural schools for over twenty years, this research was personally significant as I continue to advocate for the inclusion of field trips across the curriculum, but most particularly with my academic content - high school science.

Field trips represent one pedagogical option teachers can employ for specific curricular outcomes. At its very basic level, a field trip provides students with something other than the mind-numbing day-today routines in the classroom and may provide a unique experience to construct or reinforce meanings and connections (Roberts, 2006). Such excursions help students recognize the need for learning to read and write, as well as to understand the concepts introduced in the classroom by exposing students to a world greater than the one they inhabit from day-today and the career possibilities in that larger context (Carroll, 2007). In this study, a field trip was designed to introduce students to several vocational training programs that build upon science instruction they should have experienced in their rural high school classes but that was identified as problematic or missing.

\section{Texas Science Curriculum}

The State Board of Education (SBOE) of Texas adopts and approves the complete curriculum presented in grades K-12 for all public schools across 
the state. The content within each subject is referred to as the Texas Essential Knowledge and Skills or TEKS. Recent revisions (Texas Education Agency, $2009 \mathrm{~b}$ ) in the state's curriculum have changed and increased the requirements for high school graduation; the revisions were immediately implemented upon adoption, affecting the $9^{\text {th }}$ grade students entering that fall.

Each science course approved by the Texas SBOE is described similarly with regard to the TEKS. The first section provides a list of requirements (or recommendations such as grade level) and/or prerequisites in order to qualify for enrollment in a class. Second is a general description of the course objectives. The final (and more specific) component is the knowledge and skills content to be developed through successful completion of the course. This component is divided into two sections - scientific processes and science concepts. This is the 'meat and potatoes' of each science course and is further organized, delineated and labeled with a combination of numbers and letters (e.g., TEKS 3.E).

Although the state of Texas currently has three possible graduation plans (minimum, recommended and distinguished), there was only one graduation plan offered at the campus selected for this study the recommended plan. Chemistry and physics, the two courses chosen as the focus of the research questions, are required for both the recommended plan and the distinguished achievement plan (DAP) established by the state. The recommended plan represents a 'middle of the road' option as it requires more credits to graduate than the minimum graduation plan and was designed to prepare students for either traditional college or vocational/technical training and career options after graduation. Although both the recommended and distinguished plans require 26 credits, the recommended plan lacks some of the academic rigor of the DAP. The distinguished plan requires more foreign language courses, as well as higher-level math and science courses. Students from this particular school wishing to graduate under the DAP plan were required to enroll at the local community college for dual credit classes, with the district covering the necessary tuition and fees. When students on the campus were unable or unwilling to complete the courses required on the recommended plan, they were transferred to an alternative campus where only the minimum diploma option is available.

The TEKS for chemistry and physics include a competency, within the scientific process section (TEKS 3.E), that requires students be able to describe content from the two disciplines as they relate to future careers (Texas Education Agency, 2009a).
Because the participants purposefully selected for this study indicated an inability to realize or describe the connections as required by the TEKS, documenting the immediate impact of a careerfocused field trip created the basis for this research.

The research questions that framed this study were:

1. How do rural students describe connections between high school science content (chemistry and physics) and future careers before and after purposefully designed field trips?

2. When do the connections become evident to students?

3. What effect or impact does newly discovered connections have on students' and their families' aspirations with regard to future career or vocational options?

\section{Field Trips and Experiential Education Research in $\mathrm{K}-12$ Settings}

Experiential Education (EE) provided the theoretical framework for this research and has been defined as "learning activities that engage the learner directly in the phenomena being studied" (Wright, 2000, p. 121). Field trips are but one type of experiential education. While existing literature demonstrates that effective teaching is greatly enhanced through experiential learning (Rone, 2008), various pressures (i.e., NCLB and high-stakes test scores) have all but eliminated such experiences for public school students on most campuses nationwide (Popescu, 2008). Consequently, there is relatively little current research that addresses the efficacy of field trips or off-campus excursions in K-12 settings (Bracey, 2007; Rothstein \& Jacobsen, 2006; Baker, Jensen \& Kolb, 2002; Kolb, 1984).

As field trips, excursions and off-campus opportunities hold the promise of developing and deepening connections between academic content and real-world applications, any connection created or reinforced is most often realized through reflection on the part of the learner. Unlike the classroom, field trips are typically socially driven and conversationrich settings. They offer students a more complete picture of the total environment into which they will enter as adults and afford them a more informed viewpoint when choosing their life's work (Rothstein \& Jacobsen, 2006).

As students consider and discuss their individual and collective experiences, reflection is a natural consequence that cements and/or reinforces connections whether they are fledgling or already firmly intact. While students generally experience a reduction in conversational interactions in a typical 
adult-led classroom setting, there are indications that regular one-to-one access to adult mentors substantially increases the quality of learning in all children, but especially older children (Thomas, 1994). Curriculum-dependent field trips or excursions provide opportunities for such access. For students in rural settings, field trips may represent the only concrete examples of connections between academic content and future careers. Further, and similar to the status of rural research, there is an apparent lack of recent exploration (Rothstein \& Jacobsen, 2006) with regard to planned implementation of directed experiences (field trips) for the purpose of learning, even while this practice is common and is well-researched as an effective option in the workplace (Baker et al., 2002; Kolb, 1984). The push for high-stakes test scores under NCLB legislation is most often blamed on the reduction in field trips nationwide and on a corresponding decrease in research in this area (Bracey, 2007).

The goal of this study was to provide a collection of descriptive narrative of participants as they:

1. initially failed to identify potential connections between content and future careers;

2. experienced a field trip/excursion designed to provide opportunities to realize academic connections to careers grounded in basic science concepts; and

3. reflected on the impact of newly acquired connections with regard to vocational choices they may have realized as an immediate result of the experience.

Finally, the end product was a comparative analysis of the individual narratives using information provided by the participants in light of the original research questions.

\section{Designing the Study}

There is ample evidence to indicate that rural students are poorly represented in educational research. This study sought to investigate field trips/off-campus excursions as an effective pedagogical option in rural high school science classes. For those select students who indicated an inability to describe connections between academic content and potential careers, the researcher chose a qualitative approach, enlisting methods traditional to case study that included: participant selection through surveys, comparison of existing student records, observations and semi-structured interviews in both individual and focus group settings (Merriam, 1998).

\section{Multiple Narratives}

Case study is a research strategy that does not require the use of any particular data set or evidence collected (Yin, 1981). Because case study method seeks understanding, explanation, or description of a unique event, methods commonly used in case study were considered most appropriate for this project. Each participant's narrative was treated as an individual unit of analysis. As the study sought to describe the changes experienced by the participants and to compare those changes across the cases, multiple-case narratives represented a better choice for this study (Yin, 2003).

Multiple factors influencing the learning and achievement of students are not always easily or effectively determined through quantitative methods or instruments. In this study, the first-person accounts/narratives were organized around the research questions and presented as described by the participants (Merriam, 1998). Although not directly addressed by the research questions herein, influences affecting the participants involved in this study certainly included any number or all of the following: individual personalities of participants, aspirations of participants, educational history of participants, school environment, teacher quality, participants' experience/educational record in chemistry and physics, family socioeconomic status, parents' educational achievement and aspirations for participant, parental employment, home language, citizenship status and ethnicity. Singular narratives, focused on each of the participants, allowed inclusion of such information, lending deeper understanding of these unique participants (Yin, 2003; Merriam, 1998; Wolcott, 1994).

\section{Data Sources}

As narratives of the participants were central to this project, data were gathered through multiple means and included qualifying surveys, interviews (both individual and focus group) as well as observations. All interviews were audio recorded and, where recording was not practical, field notes were used to document interactions between participants and individuals involved in the field trip (i.e., various instructors on site and the technology center recruiter).

Data gathered from formal academic records of the participants included the following: attendance records, family income (to determine free- or reduced-lunch eligibility), family structure (oneparent, two-parent, or guardianship), parents' 
educational achievement and employment records, current GPA, science GPA, SAT/ACT scores, TAKS (Texas high-stakes test) scores, participants' aspirations and class rank.

\section{Participant Selection}

This project started in the fall of the students' $12^{\text {th }}$ grade year. The first criterion for consideration as a participant was enrollment records on the selected campus. Students had to be in the $12^{\text {th }}$ grade and continuously enrolled (on the selected campus) from the $7^{\text {th }}$ grade through the $11^{\text {th }}$ grade. This requirement ensured that no student had received science instruction that was unique or different from any other student. Because the selected school was small and offered a single graduation plan, each high school science course (grades 9-11) was assigned a particular teacher in any given year (e.g., Mrs. X taught all of the $9^{\text {th }}$ grade biology classes, Coach Y taught all of the $10^{\text {th }}$ grade physics classes, and Dr. Z taught all of the $11^{\text {th }}$ grade chemistry classes). With this arrangement, each potential participant experienced consistent exposure to science content from year to year. There were 43 students enrolled in the $12^{\text {th }}$ grade at the time this project started. Based on the requirement of continuous enrollment, 37 students qualified for potential participation and were given a qualifying survey.

\section{Data Collection}

Step one - qualifying survey. The criterionbased survey used a Likert scale and asked students to agree or disagree with general statements concerning attitudes, study habits, homework, afterschool jobs and future plans. There were also specific statements about science instruction. Those science-instruction statements simply indicated that the participants, as students, could describe connections between academic content and future jobs or training. Those who responded with agree were asked to provide an example. If the example given was appropriate, the student was considered ineligible to participate. If they responded with disagree, they were considered potential participants and passed to the next qualifying activity - an individual interview. The survey results indicated that 11 of the eligible 37 students were potential participants. Of those eleven, six were male. Three of the eleven were classified as ethnic minorities (black or Hispanic); additionally, three of the eleven either had records of previous special education services or were currently receiving them. In the period between the survey and initial qualifying survey, enrollment records were inspected to verify qualification for participation.

Step two - qualifying interviews. The first individual interview revealed that two of the eleven students should not have been included as potential participants. One male student misunderstood the statements and could appropriately describe connections. One female student did not correctly identify her enrollment as continuous from $7^{\text {th }}$ through $11^{\text {th }}$ grade; this was discovered when a review of enrollment records for the group of eleven was conducted and was further confirmed in her initial interview. The three students classified as 'minority' were disqualified from participation due to a district policy regarding credits earned toward graduation. As all three were lacking sufficient credits to remain with their $12^{\text {th }}$ grade cohort, they were transferred to the alternative campus for credit recovery, and placed on the minimum graduation plan.

The final group of eligible participants was all white, consisting of four males and two females. None had visited a single campus or post-graduation training facility. Once the purpose of the project was revealed to the remaining participants (a careerfocused field trip to the selected technology center), the two female students asked to be dropped from the study as they did not wish to participate in the research. The chief reason cited was they were both $12^{\text {th }}$ grade cheerleaders and felt their schedules would be too crowded to allow them to fully participate in the study. Incidentally, they also reported that, in their opinions, any technical/vocational training center was not a good place for girls to go to college. When asked about that comment, both anticipated a college experience that culminated in marriage, not necessarily a degree.

After consent forms were signed by parents/guardians, a review of individual academic records revealed that all four participants had been identified as 'academically at-risk' by the school district at some point during their high school years. In each case, 'academically at-risk' was defined as an expectation that the student might not graduate with his (or her) cohort. The cohort for the participants was defined as the class of students with whom they enrolled at the start of the $9^{\text {th }}$ grade. It was also revealed that all four were ranked in the bottom half of their graduating class, that they all qualified under the National School Lunch and Child Nutrition program for either free- or reduced-lunch programs, and that none of their parents (or step-parents) had experienced formal training through or possessed credentials issued by a higher education or vocational/technical agency. Only one of the 
participants lived with both biological parents; two lived in blended families with step-fathers in the home, and the remaining participant's mother was a widow with no adult male in the residence; he was an only child. They were all involved in extra-curricular sports and various other after-school activities. One participant was eligible for special education services throughout his enrollment, grades K-12 (Table 1).

\section{Table 1}

Demographics by Participant

\begin{tabular}{lllll}
\hline Description & Allen* & Doug* & Lane* & Stu* \\
Ethnicity & White & White & White & White \\
Age (at survey) & 17 & 18 & 17 & 17 \\
Lunch & Reduced & Reduced & Free & Free \\
GPA & 82.35 & 82.16 & 76.58 & 87.74 \\
Science GPA & 84.67 & 79.33 & 79.0 & 85.0 \\
Class Rank** & $27 / 39$ & $28 / 39$ & $39 / 39$ & $20 / 39$ \\
IEP in records & No & No & Yes & No \\
SAT/ACT Scores & None & None & None & 15 ACT \\
\hline
\end{tabular}

Note: *Names are pseudonyms selected by the participants on the day of the field trip. **Although the class had 43 students enrolled at the time the study began, the final class had only 39 students qualified to actually graduate.

Step three - First focus group. During the first focus interview session, the four remaining male participants selected the programs they wished to visit while conducting an Internet search of the technology center's campus website. This search was conducted as they sat together in the high school's computer lab, the only point of Internet access for the four participants. In their individual interviews, Allen, Doug and Lane all reported that they had no computers at home and therefore no Internet access. Stu was the only participant who indicated that although there was a computer in his home, 'dial-up' was the only Internet service that was affordable to his parents but had been disconnected due to slow service.

While conducting the search, the participants were asked to consider the following open-ended questions (pre-excursion) during their Internet search.

1. Tell me about the information you are finding what scientific terms do you notice or other information do you find telling how science is important to a program that is interesting to you?

2. Tell me if you are still having trouble understanding how science might be important, particularly in some program you think is interesting.

3. Tell me what you expect to discover when you visit the campus.

Because of the restrictive nature of the high school campus policy on Internet use, Stu asked: You mean we can just look around for stuff on the website? Once given permission, all four were enthusiastic but unsure how to navigate the designated website's interactive components. As they began to search, it became obvious rather quickly that the computer network provided a high speed connection but blocked a good number of options available for users. In every case, where videos were embedded for more information, participants were unable to access those links for information and further discovery. Although the videos provided were blocked, all four indicated they were interested in the diesel mechanics program. Allen thought computer programming sounded interesting because the description included the term 'gaming': he pondered: Maybe you get to sit around and play games or create your own? Lane noticed the media/telecommunications program: Hey, lookradio and television - do you get to be on the air? Very quickly, three programs (despite limited access) were selected to visit.

Step four - campus visit. The site selected for the field trip was a local vocational/technology training campus less than ten miles from the participants' high school. The facility was the site of a former military installation closed in the mid-1950s and reclaimed by the state in order to establish the vocational/technology training center in the mid1960s. Programs offered were organized under six general areas of study with over 125 professional certificates available. Student employment rates, as required by the state in order to maintain funding, must remain over $90 \%$ from year to year. 
All four participants were attentive and engaged the presenters/instructors in conversation to varying degrees. Having previously taught each of the participants, their resulting familiarity with me reduced the anxiety that was obvious once arriving on campus - an unknown and potentially threatening environment. Keenly aware that acting as a disengaged observer would not provide them with a fruitful experience, my role was one of guide and advocate (Yin, 2003), introducing them to each instructor/presenter and suggesting some questions that might reveal academic connections to the programs. Aside from a common interest in each of the selected programs, all of the participants indicated during the tour that geographic proximity and promise of job placement over a lifetime were also major considerations when researching postgraduation opportunities. The tour took four and a half hours, after which the participants dined offcampus and then met for a second focus group/debriefing session.

Step five - second focus group. Immediately following the field trip, the participants were interviewed in a second focus group setting. This interview was conducted before returning to the campus, allowing for immediate feedback and evidence of connections created as a result of their corporate experience and conversations. The following open-ended prompts/questions were provided to guide the conversations that were recorded and later transcribed:

1. Tell me what you learned this morning about science needed in the programs we visited.

2. Was there a point when you realized that science was important in each of the programs?

3. How much science do you already know that would be used in a program you saw?

4. Tell me about other jobs you realized or believe might use science that you know.

During the ensuing 90-minute conversation, participants considered and addressed the prompts collectively and revealed several common lines of thought, often agreeing and further reinforcing their individual and group debriefing of their experience. Typical comments included:

Just about everything we saw today had something to do with math and science...the lighting and sound stuff uses a lot stuff we learned in physics... and I didn't know you had to know so much stuff about math for those computer things, I never heard of some of it...codes and stuff. [Stu]

There was a lot of stuff I never thought about with cameras in the studio, angles and stuff...that's math, right? The sound boards and light monitors...there was a lot of equipment I didn't know it took that much for a radio or $T V$ show to be done. And the diesel mechanics guy with the equations...the hydraulics and stuff like that. [Doug]

Something else I saw out there, it was airbrushing painting...I didn't know you could study stuff like that at college...I mean, I guess that's a college class, right? And working on airplanes? That was really cool. I thought that was really cool that we could go in the hangar and look at where they were working on them. [Lane]

Yeah, I know - I liked seeing like the airplanes and how they are built, where all the different controls are. And all of the diesel mechanics stuff, all of the training involved for the different engines, because there's a lot more to it than just a regular car. [Allen]

Step six - final interview. A second, and final, individual interview was conducted 7-10 days later, allowing the participants time to share their newfound information with parents. The purpose of the second interview was to assess any changes in post-graduation plans for college, vocational or technical training. During this final session, the following open-ended prompts/questions were provided to allow students' reflections on the experience to be fully explored:

1. Tell me what you understand now about the need to study science in high school.

2. We took a field trip in the second semester of your senior year. When would it have been more helpful to you...to help you understand why science classes are important in order have a good job and/or college options after you graduate? Why do think that would be the best time to visit off-campus?

3. After you shared this information from the field trip with your parents, how did your plans and their support change?

As in both focus group sessions, comments from the participants were typical of normal conversation, with comments and answers overlapping and reiterated, providing deeper understanding of their experiences as the interviews progressed. The following comments are combinations of both unique and commonly shared insights revealed in each interview.

I didn't know so much science and math would be important...I mean I thought computers would be interesting but it is ridiculous...I don't get why you'd have to have so much math to do codes and stuff to make up games... if you have to 
do that, then I didn't get nearly enough (referring to math skills). [Stu]

The freshman or sophomore year. Earlier than that, you don't know what you're doing - it's just a trip to get out of class. That's about when you start trying to figure out what you're doing.

[Lane]

Considering that nobody in my family has gone to college, they'd support me. They want me to finish. They would support me, no matter what I do. [Stu]

I think junior high might be a good time to start. Kids don't know what they might want to do yet, but they could start seeing some things instead of just talking about it or seeing it in books. [Allen]

When I found out they had programs to help you pay for it and that it was cheaper than any of the other colleges around, my parents were really glad. They also have to help you find a job from now on...that's good. [Doug]

I really wish I'd paid more attention in physics I didn't know you could figure out so much stuff about...well, everything basically...I wasted a lot of time but I guess they can teach me what I need to know...this time, I'll pay more attention, 'cause I'll be paying for it (laughing). [Allen]

\section{Individual Narrative Analysis}

All qualitative research seeks to provide a descriptive component, but description alone is not a sufficient reason to conduct research (Merriam, 1998). The data provided in this study are a collection of narratives, investigating the effectiveness of experiential education (EE) when applied to older, adolescent participants (Creswell,
1997). Analysis under the qualitative framework tends to work from the ground up, dealing with a specific problem(s) and eventually producing a hypothesis or solution to the problem under investigation (Lichtman, 2006). Inductive analysis of the participants' perceptions as they moved through the excursion experience provided evidence of EE effectiveness. The inductive approach proved effective when working with the data from each participant, subjected to analysis as it was collected. The demographic data, collected prior to the excursion, is summarized on Table 1. Measures taken to establish internal validity included triangulation, member checks, participant involvement and researcher bias (Merriam, 1998). External validity is in evidence as transferability to similar populations would be expected to render similar results (Yin, 2003).

\section{Analysis across the Narratives}

Each narrative was subject to identical and separate scrutiny in light of the original research questions and related strands of inquiry that emerged as a result of conversations (Creswell, 1997). Again, using the same research questions as focal points, the individual narratives were collectively analyzed for responses that were considered generalizable or similar through an open coding of the transcribed individual interviews and focus group settings (Merriam, 1998). Table 2 provides the results of the coding process in light of:

1. the ability to describe connections between content before and after the field trip;

2. recognizing a singular event when connections were realized; and

3. the perceived impact on future plans on the part of participants and parents/guardians.

Table 2

Summary of Analysis across the Narratives

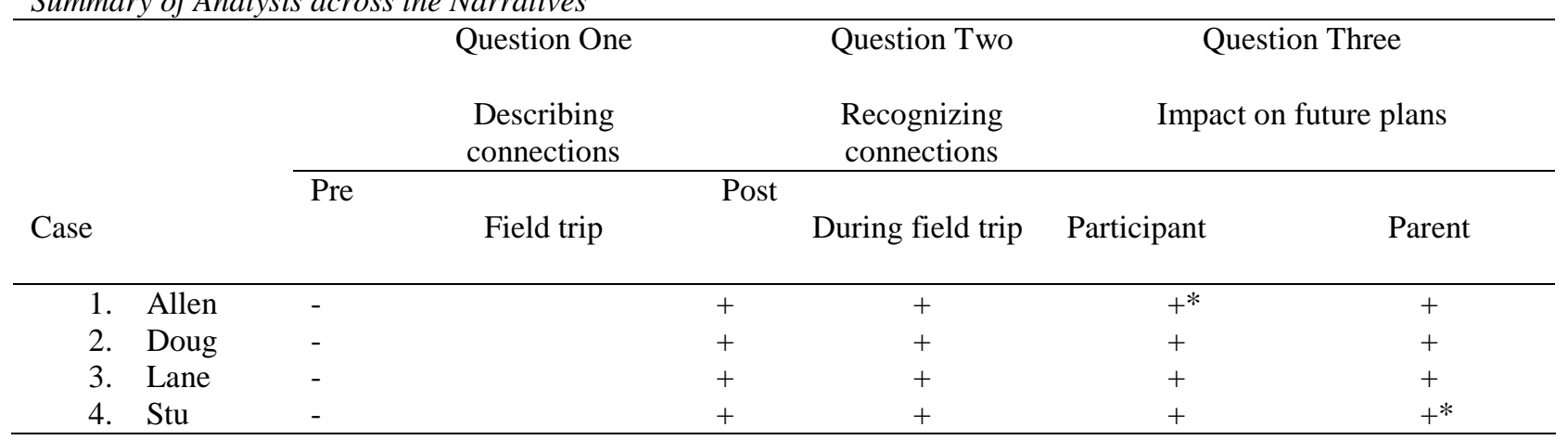

Note: - Negative Response; + Positive Response; * Greatest Increase in Response 


\section{Discussion}

\section{Research Question 1 - An Inability to Describe Connections}

The first area of research explored the changes in perception and ability to describe connections between academic science content and careers as experienced by the participants immediately following the field trip. Common characteristics of the participants included step-parent or widowedparent households, economically-stressed households (allowing enrollment in the National School Lunch and Child Nutrition Program), active participation in multiple extra-curricular activities, local church membership and/or attendance, and membership in volunteer after-school organizations - all were members of the volunteer fire department. Academically, all were ranked in the lower half of their graduating class, found science content confusing and/or incomprehensible at times, and were not interested in science classes beyond those required for graduation. None had experienced any field trips that were science or career-specific (e.g., museums, zoos, or any available from local venues or industry) nor had any of the participants visited any colleges or vocational training facilities at the time of the initial surveys and first individual interviews.

When interviewed initially about participating in the project, each participant indicated that he would probably not enroll for additional science courses because, as Doug commented, studying science sometimes makes me anxious or nervous. Additionally, the common comment, Why would I? I don't have to take any more science to graduate, was an indication of the collective negative association these students had with science content. However, when they were asked about participating in a field trip and visiting a training center, typical responses were, A field trip? Yes! and It's a chance to see a school-haven't visited one yet. Without the suggestion that they would have to report anything specifically observed, this project provided participants with a single field trip experience, designed to ensure exposure to some previously taught science content in multiple vocational settings.

\section{Research Question 2 - Initially Identifying Connections}

The second area of research focused on a specific instance that participants could identify as central to realizing connections between academic science content and future careers. The participants all reported connections were created in one particular setting, during the diesel mechanics program tour. The faculty member conducting the classroom tour explained the need for basic physics equations and metric conversions, used in both chemistry and physics classes, to the participants. While participants had unanimously reported their high school physics class as a very negative experience, they agreed that this instructor demonstrated a practical, common sense use of knowledge and skills. Allen's comment was perhaps the best: When we walked into that one classroom with the formulas on the board...it looked just like the equations from the physics class at school. Further Allen was impressed with the practical approach taken by the instructor to solve a problem common to most science students.

The guy said he had trouble with the difference between metric tools and our (standard) tools and he ended up making his own conversion chart that he put in his wallet so he wouldn't keep getting confused. I never thought about making my own cheat sheet [laughing]. That was a BIG surprise to me.

This comment drew immediate agreement from Doug, Lane and Stu.

The next two programs visited were computer programming and media/telecommunications. While initially excited about those programs, the participants as a group were decidedly less enthusiastic once realizing that both would require additional college math classes. Misconceptions with both programs also involved notions such as, computers would be fun because you could make up games and stuff, not realizing the critical need for advanced mathematics. With regard to the computer program department, Stu's comment was affirmed by the other participants - That computer thing or whatever? There were so many codes, so much math...stuff like that for (creating) games? It's ridiculous. The media/telecommunications program met with similar (negative) reactions once they realized not only the heavy reliance on instrumentation when working with light, sound and projection, but also the decided lack of 'face time' in front of the camera.

\section{Research Question 3- Changes in Participants' Perceptions}

The final area of research dealt with potential changes in students' plans or perceptions with regard to career options not previously realized or identified. All of the participants anticipated some type of career training or college prior to the field trip. As a result of this singular experience, during their final individual interviews, each participant agreed that this should be a 'connecting piece' included in 
science and other academic content areas allowing students to begin understanding the need for said content in the workplace. Their suggestions for appropriate grade level inclusion ranged from $7^{\text {th }}$ to $10^{\text {th }}$ grade, with the most common grade level reported as the sophomore or $10^{\text {th }}$ grade year.

\section{Conclusion}

Like many rural schools in central Texas and across the country, teacher quality is a critical concern. This study began in the fall of 2009. The number of science teachers returning to the school under study was $20 \%$ ( 1 out of 5). All of the high school teachers were assigned middle school classes to teach in addition to their high school courses and all taught what was considered a full load, six classes per day. In the four years the participants were enrolled, four different physics teachers and three different chemistry teachers were hired, stayed for a year or two and then resigned or were refused subsequent contracts. With such high turnover, it is difficult to assume that the science faculty had much understanding of problems unique to isolated, rural youth or that they had much impact on the resulting knowledge and/or skills gained by students. Due to the fact that the district is located fairly near a large campus with an education department as well as two programs offering alternative certification, a relatively sure supply of teachers is available. The high school science teachers who came and went during this period of time were all from one of these credentialing programs. Of the seven high school science teachers who taught the cohort of participants, five were not offered subsequent contracts, four due to a lack of competence or misconduct in the classroom and one for criminal behavior involving students; one left mid-year for personal reasons and did not return the following year. One physics teacher left during this period because he accepted a teaching job closer to aging parents. An area for future research may be the effect of science teacher transience on science connections/career choice of rural school students.

The rural school district that served as the focus of this study receives minimal federal funding based on its average daily attendance (ADA), a direct consequence of small enrollment. With regard to state funding, this particular district receives the least funding possible under the current formulas because it is considered a 'small school by choice' - there are four other somewhat larger rural districts within twelve miles in which students could enroll and boost the ADA levels. It is important to note that while twelve miles may seem like a short distance, local community identity and membership is determined by the high school attended and a source of local pride. Not only do these funding restrictions negatively affect pay for teachers, another consequence is a reduced curriculum and few program options. All enrolled students are expected to graduate under a single graduation plan. Every student therefore, regardless of ability or lack thereof, is expected to complete the requirements under that plan in order to graduate. Students at the extremes of abilities are left to fend for themselves. This often results in special needs students falling behind, becoming 'at-risk' for graduation and, for some, ultimate placement in an alternative high school setting where the basic, and possibly more appropriate, diploma becomes an option.

Field trips/off-campus excursions designed around basic curriculum represent a crucial option for students everywhere. Particularly when faced with high faculty turnover and a lack of adult role models at home, students' understandings of the work world they will enter are fragile. Field trips provide an opportunity to establish practical experiential backgrounds against which students can make more informed decisions regarding their plans after graduation. Informal education of this type has been valued and practiced by countless generations. It was strongly supported by Dewey and others in the early $20^{\text {th }}$ century. By the end of that same century, field trips were and continue to be a casualty of No Child Left Behind (NCLB) legislation (Popescu, 2008). The participants in this study were $12^{\text {th }}$ grade students in a rural school setting who, except for athletic and/or extracurricular events, had experienced no offcampus academically-driven excursions during their high school years. Although the high school was located fewer than fifteen miles from three different vocational/technical and traditional campuses, they had not visited any of the three (nor any other facility) during their entire high school enrollment. Their narratives indicated that a singular, welldesigned, purposeful field trip can have significant effects on their ability to conceptualize the need for content presented in the classroom.

\section{Significance and Implications of this Study}

This research touched on two specific areas in which relatively small knowledge base exists. The first underlying area critical to this study is rural education. For those interested in or actively researching rural education, the statistics are well known and heavily documented. Some of the more recent statistics available indicate that over $30 \%$ of the nation's public schools are located in communities described as rural. The number of students attending rural schools nationwide remains 
consistently around or slightly less than $20 \%$ (Gandara, Gutierrez \& O’Hara, 2001). Despite their number and impact on educational outcomes, rural public schools and their student populations are statistically underrepresented in current educational research, generally accounting for less than $6 \%$ of the sampled population in some recent studies (Hardre, et al., 2007). Rural schools have more diverse populations, higher rates of poverty, and higher numbers of single or no parent households than most urban schools. Since rural property values are generally lower than urban or suburban properties, rural schools typically have lower tax revenues with which to supplement teacher state salaries and experience greater difficulty attracting and retaining highly qualified teachers (Hardre, 2007). Isolation is a typical feature of many rural schools and, with 340 of the poorest 386 counties in the US classified as rural (Lichter \& Johnson 2006), the lack of research is often indicative of difficulties encountered by researchers when investigating these schools (Springer \& Gardner, 2010). While this research project took less than one school year to complete, the relationships that made it possible and comfortable for all involved took four years to establish. This is but one of the difficulties encountered when qualitative, rich descriptions of rural problems are desired.

The second area is experiential education in grades K-12. In concert with traditional educational theory and practice, the purposefully designed excursion proved a positive experience for each of the participants involved. This field trip was designed with an emphasis on careers requiring some degree of science content commonly taught in high school science classes. The positive impact of a single, purposeful field trip suggests that students can successfully develop connections between academic

\section{References}

Bialeschki, M.D. (2007). The three Rs for experiential education researchers. SEER 2006 opening address. Journal of Experiential Education, 29(3), 366-38.

Baker, A., Jensen, P. J., \& Kolb, D. A. (2002). Conversational learning: An experiential approach to knowledge creation. Westport, CT: Quorum Books.

Bracey, G. (2007). School's impact out of school. Phi Delta Kappan, 89(3), 236-237.

Carroll, K. (2007). A guide to great field trips. Chicago, IL: Zephyr Press.

Creswell, J. (1997). Qualitative inquiry and research design: choosing among five traditions. Thousand Oaks, CA: Sage. content and future careers when placed in appropriate contexts. This may be particularly true for students who are academically challenged or described as 'atrisk' due to low performance on high-stakes tests or performance in the classroom and, like these participants, have little or no opportunity for academic field trips.

Experiential education, in the form of field trips or off-campus excursions, deserves further investigation in K-12 settings. With its successful application at the corporate and higher education levels, it stands to reason that basic learning styles remain fairly unchanged. In simpler terms, what works when you are an adult is quite likely what worked when you were younger. The overall positive results of this study, from describing connections to increased awareness as well as expanded awareness of other programs and opportunities, would indicate that field trips should be further studied as effective pedagogy in rural high school science classes. If this is indeed an effective option for 'at-risk' rural high school students, field trips may represent an effective pedagogy for all high school students across the curriculum because they may all be 'at-risk' to some degree.

At the end of it all, comments like Doug's Could we come back tomorrow? I mean this was good today, I'd like to see some other programs, were the greatest indicator of the success of this project. Who knew, Lane chimed in, there was so much out there to do? And to see? This was really exciting, a little confusing and kinda scary, but still...this was terrific! Students deserve the best we can provide when it comes to educational practice. Field trips represent one of the best, most proven, pedagogical options available. Advocate for your students - go out on a limb, insist on field trips...or, on second thought, go out on a bus.
Gandara, P., Gutierrez, D., \& O'Hara, S. (2001). Planning for the future in rural and urban high schools. Journal of Education for Students Placed At Risk, 6(1 \& 2), 73-93.

Hardre, P. L. (2007). Motivating environments: A systemic analysis of four rural high schools. Leadership and Policy in Schools, 6, 231-265.

Hardre, P. L., Crowson, H. M., Debacker, T. K., \& White, D. (2007). Predicting the academic motivation of rural high school students. The Journal of Experimental Education, 75(4), 247-270.

Kolb, D. A. (1984). Experiential learning: Experience as the source of learning and development. Englewood Cliffs, NJ: Prentice-Hall. 
Lichtman, M. (2006). Qualitative research in education: A user's guide. Thousand Oaks, CA: Sage.

Merriam, S. B. (1998). Qualitative casework and case study application in education. San Francisco: John Wiley \& Sons.

Popescu, R. (2008). No child outside the classroom. Newsweek, 151(6), 12.

Roberts, T. G. (2006). A philosophical examination of experiential learning theory for agriculture educators. Journal of Agriculture Education, 47(1), 17-29.

Rothstein, R. \& Jacobsen, R. (2006). The goals of education. The Phi Delta Kappan, 88 (4), 264-272.

Rone, T. R. (2008). Culture from the outside in and the inside out: Experiential education and the continuum of theory, practice and policy. College Teaching, 56(4), 237-245.

Scarce, R. (1997). Field trips as short-term experiential education. Teaching Sociology, 25(3), 219-226.

Springer, M., \& Gardner, C.D. (2010). Teacher pay for performance: Context, status and direction. Phi Delta Kappan, 91 (8), 8-15.
Texas Education Agency. (2009a). Graduation Rates. Retrieved from http://ritter.tea.state.tx.us/cgi/sas/broker

Texas Education Agency. (2009b). Texas Administrative Code (TAC), Title 19, Part II, Chapter 112. Texas Essential Knowledge and Skills for Science. Retrieved from http://ritter.tea.state.tx.us/rules/tac/chapter112/index. html

Thomas, A. (1994). Conversational learning. Oxford Review of Education, 20(1), 131-142.

Wolcott, H. F. (1994). Transforming qualitative data: Description, analysis, and interpretation. Thousand Oaks, CA: Sage.

Wright, M. C. (2000). Getting more out of less: The benefits of short-term experiential learning in undergraduate sociology courses. Teaching Sociology, 28(2), 116-126.

Yin, R.K. (1981). The case study crisis: Some answers. Administrative Science Quarterly, 26(1), 58-65.

Yin, R. K. (2003). Case study research: Design and methods. Thousand Oaks, CA: Sage.

Tommye Hutson is a science teacher and has worked in southern rural classrooms for the past 25 years. Her research interests include equity in education, teacher education and rural education. She continues to work with rural teachers in central Texas, concentrating on STEM initiatives and field trips. She would like to sincerely thank both Dr. Cooper and Dr. Talbert who worked diligently as collaborators and mentors on this project. 